\title{
ULTRASTRUCTURAL STUDY OF HUMAN SPERM ACROSOME DURING ACETIC ACID EXTRACTION OF ACROSIN
}

\author{
H. H. WOLFF AND W.-B. SCHILL \\ Department of Dermatology, University of Munich, \\ D-8000 Munich 2, Federal Republic of Germany
}

(Received 31st fuly 1974)

\begin{abstract}
Summary. During acrosin extraction from human spermatozoa by acetic acid treatment, severe ultrastructural alterations are observed: loss of the plasma membrane and of parts of the outer acrosomal membrane, total depletion of the acrosomal content, disappearance of the equatorial segment. The inner acrosomal membrane and the nucleus appear unchanged. The alterations are reduced by glycerol pretreatment in spite of improved extraction of the enzyme.
\end{abstract}

Acetic acid extraction has been found to improve quantitative determination of acrosin activity (Fink, Schiessler, Arnhold \& Fritz, 1972; Fritz, FörgBrey, Fink, Meier, Schiessler \& Schirren, 1972). In addition, pretreatment with glycerol leads to a significant increase of the extractable acrosin activity in most cases (Schill, 1974). The alterations occurring in sperm heads and acrosomal caps during the acetic acid extraction at the ultrastructural level have not been previously reported. Fresh human ejaculates characterized by normal sperm counts and normal sperm morphology were obtained from two healthy donors after 5 days of sexual abstinence and were used $1 \mathrm{hr}$ after liquefaction. The ejaculates were divided into two samples of $0.5 \mathrm{ml}$. The first sample was washed twice in $0.9 \%$ saline $\left(600 \mathrm{~g}, 4^{\circ} \mathrm{C}, 20 \mathrm{~min}\right)$ and divided into two portions. One portion served as control, the other $(0.25 \mathrm{ml})$ was treated with an aliquot of $2 \%$ acetic acid for $30 \mathrm{~min}$ at room temperature.

The second sample was gently mixed with glycerol to a final concentration of $10 \%(\mathrm{v} / \mathrm{v})$, equilibrated for $30 \mathrm{~min}$ at room temperature, washed twice as indicated above, and divided into two portions. One portion served as control, the other was treated with acetic acid as indicated above.

The spermatozoa in all the samples were examined by electron microscopy after the methods of Stefanini, De Martino \& Zamboni (1967) and Schill \& Wolff (1974b). Simultaneously, the supernatants of the samples treated with acetic acid were used for acrosin determination (Schill, 1973).

The ultrastructure of a typical normal human sperm head after routine preparation is shown in Pl. 1, Fig. 1. The structural details described by Pedersen $(1969,1972)$ and Schill \& Wolff $(1974 b)$ were easily distinguished. 
No significant differences were observed in spermatozoa pretreated with $10 \%$ glycerol.

The spermatozoa subjected to acetic acid treatment showed severe alterations of their ultrastructure (Pl. 1, Fig. 2). Usually, the cellular envelope was completely removed. The outer acrosomal membrane was extensively shed and, where present, showed decreased electron density and several breaks. Total depletion of the acrosomal content had taken place. The inner acrosomal membrane presented a wavy appearance and strong electron density, but usually remained intact. The specialized posterior part of the acrosome, the equatorial segment, was no longer detectable, probably due to a dissolution of the contacts between outer and inner acrosomal membranes which normally are characteristic of this region. Plate 2, Fig. 3 gives an impression of additional severe morphological changes that take place in the neck region and in the mid-piece after treatment with acetic acid. The nuclear chromatin appeared unchanged.

After preincubation with $10 \%$ glycerol the alterations of the sperm head membrane systems following treatment with acetic acid were less pronounced (Pl. 2, Fig. 4). Large parts of the cellular envelope were still present. Both acrosomal membranes usually remained intact, whereas most of the acrosomal contents seemed to be extracted. Fine granular electron-dense material was frequently attached to parts of the cellular envelope, and to most of the outer and inner acrosomal membranes.

Our previous work combining electron microscopy of human spermatozoa during different steps of cryo-preservation and of acrosin determination after extraction of the spermatozoa with acetic acid indicated an association of the acrosomal proteinase with the inner acrosomal membrane and/or the equatorial segment (Schill \& Wolff, 1974a, b). Treatment with acetic acid leads to almost complete extraction of acrosin activity from human spermatozoa (Fritz et al., 1972; Schill, 1973) and significant alterations of acrosomal structures were observed in our study (Pl. 1, Fig. 2 and Pl. 2, Fig. 3). The inner acrosomal membrane, however, remained almost completely intact and even showed increased electron density. This observation indicates that the acrosomal proteinase may be removed from the inner acrosomal membrane and/or the equatorial segment without the severe alterations of these membranes at the ultrastructural level that have been shown after detergent treatment (Churg, Zaneveld \& Schumacher, 1974). This phenomenon may be compared to physiological conditions in vivo when the enzyme is released during the penetration of the sperm head through the zona pellucida. During this process, the inner acrosomal membrane has been shown to remain intact (Bedford, 1970; Soupart \& Strong, 1974). From our experiments, as well as from the action of the enzyme in situ on gelatine plates (Gaddum-Rosse \& Blandau, 1972), it is assumed that only weak bonds are responsible for the attachment of the enzyme to the membranes. The nature of these bonds is not known. Under normal conditions, no obvious ultrastructural differences between the outer and inner acrosomal membranes are detectable, but in our experiments, following exposure of the spermatozoa to acetic acid, the inner acrosomal membrane proved much more stable and appeared significantly more electron- 
PI.ATE 1

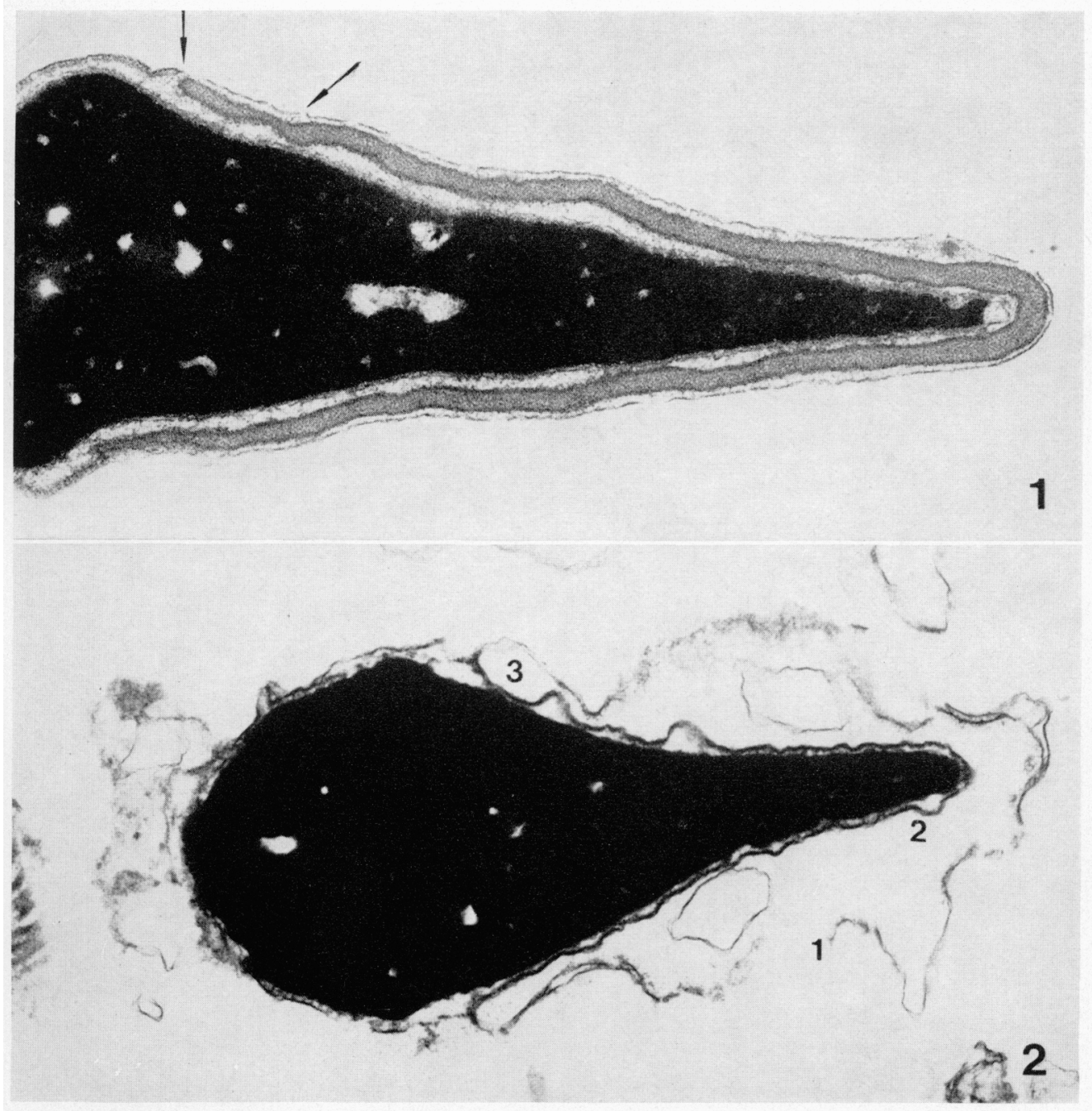

Fig. 1. Control. Normal human sperm head. The acrosomal structures are well preserved. The equatorial segment is marked by arrows. From without inwards, the following structures are visible: the cellular envelope showing a few breaks due to washing and fixation procedures, the submembranous space, the outer acrosomal membrane, the homogeneous acrosomal content of moderate electron density, the inner acrosomal membrane, the subacrosomal space, the nuclear envelope, and the dense coarsely granular chromatin material. $\times 50,000$.

Fig. 2. Acetic acid treatment. The plasma membrane is lost and the acrosomal contents are depleted. 1, Outer acrosomal membrane; 2 , inner acrosomal membrane; 3 , region of equatorial segment. $\times 37,000$. 
PI.ATE 2

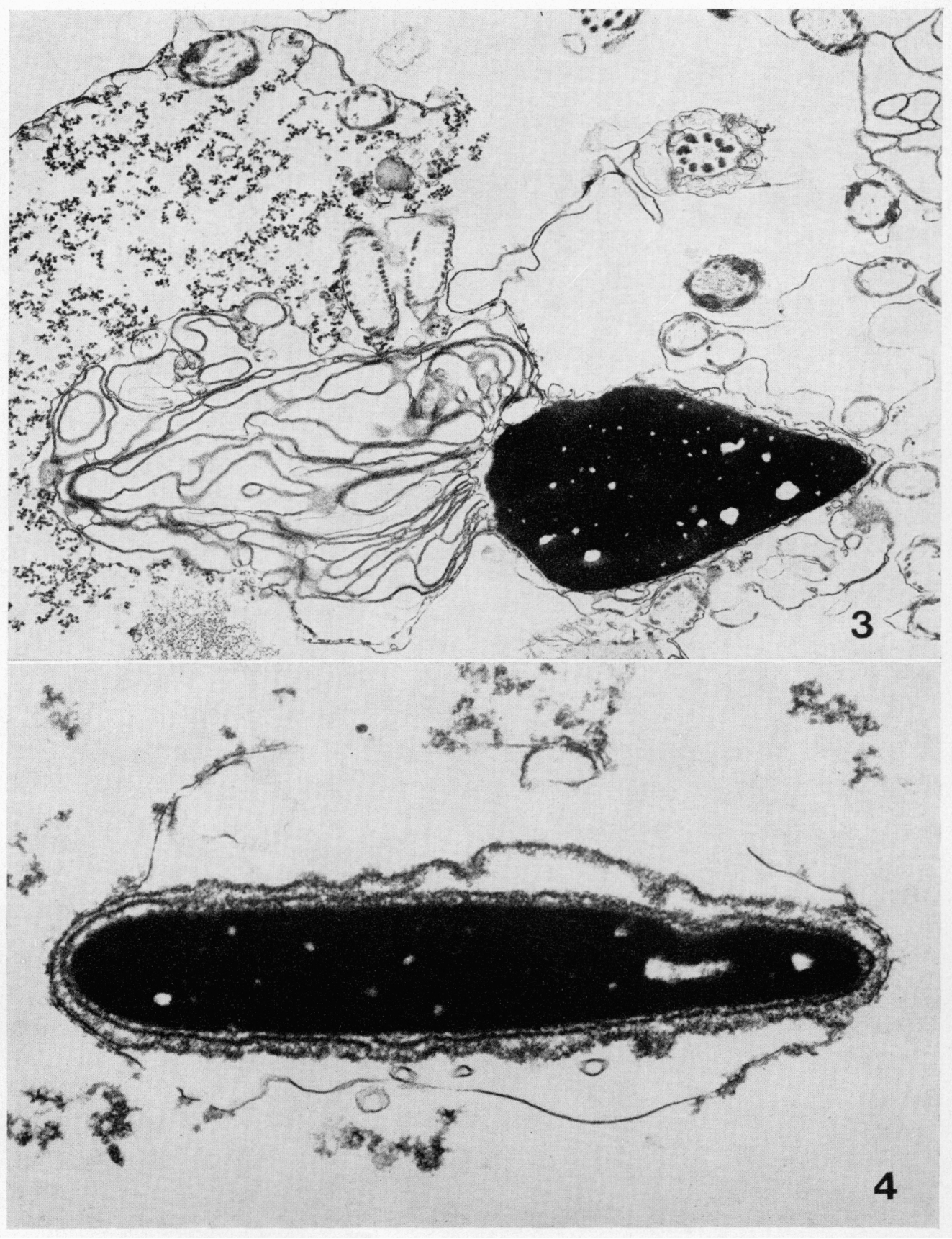

FIg. 3. Acetic acid treatment. There are severe alterations of acrosomal, neck and mid-piece membrane systems. $\times 20,000$.

FIG. 4. Glycerol and acetic acid treatment. There is improved preservation of membranes which are covered by fine granular material. $\times 40,000$. 
dense than the outer acrosomal membrane. This different behaviour under experimental conditions proved that considerable morphological and probably functional differences exist.

Glycerol is known to have protective effects on membrane and protein structures (Mann, 1964). These effects are obvious in our electron micrographs (see Pl. 2, Fig. 4). As compared to the controls, larger parts of the plasma membrane and most of the membranes of the acrosomal cap were preserved and most of these membranes were covered by fine granular electron-dense material. Biochemical methods have shown increased acrosin activity after pretreatment with glycerol (Schill, 1974). The ultrastructural results presented here indicate that this increased activity is due to effects of glycerol on the sperm membranes which lead to improved extraction of the enzyme.

This work has been supported by the Deutsche Forschungsgemeinschaft. We thank Miss E. Januschke and Miss I. Estelmann for their technical assistance.

\section{REFERENCES}

Bedford, J. M. (1970) Sperm capacitation and fertilization in mammals. Biol. Reprod., Suppl. 2, $128-158$.

Ghurg, A., Zaneveld, L. J. D. \& Schumacher, G. F. B. (1974) Detergent treatment of human and rabbit spermatozoa: ultrastructural changes and release of middlepiece enzymes. Biol. Reprod. $10,429-431$.

Fink, E., Schiessler, H., ARnhold, M. \& Fritz, H. (1972) Isolierung eines Trypsin-ähnlichen Enzyms (Akrosin) aus Eberspermien. Hoppe-Seyler's Z. physiol. Chem. 353, 1638-1645.

Fritz, H., Förg-Brey, B., Fink, E., Meier, M., Schiessler, H. \& Schirren, G. (1972) Humanakrosin: Gewinnung und Eigenschaften. Hoppe-Seyler's Z. physiol. Chem. 353, 1943-1949.

Gaddum-Rosse, P. \& Blandau, R. J. (1972) Comparative studies on the proteolysis of fixed gelatin membranes by mammalian sperm acrosome. Am. F. Anat. 134, 133-143.

Mans, T. (1964) The Biochemistry of Semen and of the Male Reproductive Tract, pp. 362-363. Methuen, London.

Pedersen, H. (1969) Ultrastructure of the ejaculated human sperm. Z. Zellforsch. mikrosk. Anat. 94, 542-554.

Pedersen, H. (1972) Further observations on the fine structure of the human spermatozoon. Z. Zellforsch. mikrosk. Anat. 123, 305-315.

Schil., W.-B. (1973) Acrosin activity in human spermatozoa: methodological investigations. Arch. derm. Forsch. 248, 257-273.

Scrill, W.-B. (1974) The influence of glycerol on the extractability of acrosin from human spermatozoa. Hoppe-Seyler's Z. physiol. Chem. 355, 225-228.

Schilt, W.-B. \& WolfF, H. H. (1974a) Acrosin activity and acrosome ultrastructure of human spermatozoa after freeze preservation. Naturwissenschaften, 61, 172.

Schil, W.-B. \& WolpF, H. H. (1974b) Ultrastructure of human sperm acrosome and determination of acrosin activity under the conditions of semen preservation. Int. F. Fert. (in press).

Soupart, P. \& Strong, P. A. (1974) Ultrastructural observations on human oocytes fertilized in vitro. Fert. Steril. 25, 11-44.

Stefanini, M., De Martino, G. \& Zamboni, L. (1967) Fixation of ejaculated spermatozoa for electron microscopy. Nature, Lond. 216, 173-174. 